\title{
Hubungan Tingkat Pengetahuan Petugas Pengelola Obat dengan Tingkat Ketersediaan Obat di Puskesmas Kota Malang
}

\author{
Machrozi Alfian ${ }^{1 *}$, Ayuk Lawuningtyas Hariadini ${ }^{1}$, Bambang Sidharta ${ }^{1}$ \\ ${ }^{1}$ Jurusan Farmasi, Fakultas Kedokteran, Universitas Brawijaya, Malang, Indonesia
}

\section{INFO ARTIKEL}

Sejarah artikel:

Penerimaan

naskah: 30 Juli

2020

Penerimaan

naskah revisi: 10

Desember 2020

Disetujui untuk

dipublikasikan: 10

Desember 2020

2020

\section{Kata kunci : \\ Puskesmas,Pengel \\ olaan \\ Obat,Pengetahuan \\ ,TingkatKetersedi \\ aan}

\section{A B S T R A K}

Pengelolaan obat merupakan kegiatan mengelola sediaan farmasi untuk menjamin keamanan produk, dan terhindar dari kerusakan fisik maupun kimia. Indikator yang dapat digunakan salah satunya adalah tingkat ketersediaan obat. Tingkat ketersediaan obat didapatkan dari nilai persentase jumlah obat yang diperlukan di puskesmas harus sesuai dengan keperluan masyarakat sehingga jumlah obat di gudang puskesmas minimal harus sama dengan jumlah stok selama waktu tunggu kedatangan obat. Petugas pengelola obat harus memiliki pengetahuan tentang pengelolaan obat di puskesmas. Penelitian ini bertujuan untuk mengetahui hubungan tingkat pengetahuan petugas pengelola obat dengan tingkat ketersediaan obat di beberapa Puskesmas Kota Malang. Penelitian yang dilakukan merupakan observasional analitik cross sectional. Teknik pengambilan sampel responden adalah dengan total sampling. Instrumen yang digunakan adalah kuesioner pengetahuan petugas pengelola obat dan lembar pengumpul data tingkat ketersediaan yang dilihat dari data LPLPOyang telah dinyatakan laik etik oleh Komisi Etik PenelitianKesehatanFakultas Kedokteran Universitas Brawijaya dengan SK No. 81/EC/KEPK-S1FARM/04/2020. Hasil rata-rata persentase pengetahuan 10 petugas adalah $84,32 \%$, yang termasuk dalam kategori baik. Hasil rata-rata persentase tingkat ketersediaan obat adalah 64,19\%. Kategorisasi persentase tingkat ketersediaan obat terdiri dari 10\% dengan kategori baik, 70\% dengan kategori cukup, dan 20\% dengan kategori kurang. Hasil uji statistik korelasi dengan Uji Rank Spearman menunjukkan nilai Spearman Correlation adalah 0.034 atau $\mathrm{p}=0.870(\mathrm{P}>0,05)$, menunjukkan bahwa tidak ada hubungan antara tingkat pengetahuan petugas pengelola obat dengan tingkat ketersediaan obat di puskesmas Kota Malang.

\section{Correlation between Pharmaceutical Staffs' Level of Knowledge and Drug Management in Primary Health Centre (PUSKESMAS) in Malang City}

\section{Keywords:}

Puskesmas, Drug

Management,

Knowledge,

Availability Level

\section{A B S T R A C T}

Drug management is the activity of management and storage of pharmaceutical preparations in an appropriate place, which aims of ensuring product safety and avoiding physical or chemical damage. One of the indicators that can be utilized in analysing drug management processes is the level of drug availability. The level of drug availability is a value that shows the percentage of the number of drugs required for healthcare services in health centres that must be in line with the needs of the population. Therefore, the number of drugs in the warehouse of the Primary Health Centre (Puskesmas) must be at least comparable to the amount of stock during the waiting time for the arrival of drugs. The staff must be knowledgeable about drug management at the Puskesmas. This research aims to determine the relationship between the level of knowledge of drug management of the staff with the level of drug availability in several Puskesmas in Malang. The research carried out was cross sectional analytic observational. The sampling technique of respondents was total sampling. The instrument used was a questionnaire of the knowledge of drug management of the staff and a data collection sheet for the drug availability obtained from the LPLPO datawhich hasethical clearance by the Medical Research Ethics Commission of the Faculty of Medicine, Universitas Brawijaya No. 81 / EC / KEPK-S1-FARM / 04/2020. The result of the average percentage of staff knowledge is $84.32 \%$, which was included in the good category. The average percentage of drug availability is $64.19 \%$. The percentage categorization of the level of drug availability comprises of $20 \%$ with good category, $70 \%$ with moderate category, and $10 \%$ with poor category. The results of the statistical correlation test using the Spearman Rank test indicate the Spearman Correlation value of 0.034 or $\mathrm{p}=0.870(\mathrm{p}>0.05)$, indicating that the correlation is no meaningful relationship between The Level of Knowledge of Drug Management of The Staff With The Level of Drug Availability in Primary Health Centre (PUSKESMAS) in Malang City. 



\section{Pendahuluan}

Pelayanan kesehatan bertujuan untuk menaikan derajat dan kesejahteraan masyarakat terutama dalam bidang kesehatan. Seluruhmasyarakat mempunyai hak yang sama untuk memperoleh pelayanan kesehatan, danpemerintah memiliki tanggung jawab penuh untuk memenuhi ketersediaan segala bentuk pelayanan kesehatan yang efisien, bermutu dan terjangkau yang diperlukan oleh seluruh masyarakat. Salah satu upaya pemerintah yaitu dengan meningkatkan ketersediaan dan pemerataan fasilitas pelayanan kesehatan dasar seperti Puskesmas disetiap daerah ${ }^{1}$.Pusat kesehatan masyarakat (Puskesmas) merupakan suatu organisasi pelaksana upaya kesehatan tingkat pertama yang memiliki tanggung jawab untuk memberikan pelayanan kesehatan kepada seluruh masyarakat yang berada disekitar daerah tersebut. Dengan adanya puskesmas diharapkan masyarakat dapat mendapatkan pelayanan kesehatan yang bermutu dengan mudah dan biaya yang terjangkau oleh masyarakat umum ${ }^{1}$.

Manajemen obat merupakan suatu rangkaian kegiatan paling penting yang berguna dalam pembangunan kesehatan yang menyangkut aspek yang terdiri dari beberapa kegiatan, mulai dari perencanaan, permintaan, penerimaan, penyimpanan, pendistribusian, pengendalian, pencatatan dan pelaporan, serta pemantauan dan evaluasi ${ }^{2}$. Tujuan manajemen obat adalah tersedianya obat setiap saat dibutuhkan baik mengenai jenis, jumlah maupun kualitas secara efesien, dengan demikian manajemen obat dapat digunakan sebagai proses penggerakan dan pemberdayaan semua sumber daya yang dapat dimanfaatkan untuk mewujudkan ketersediaan obat ketika dibutuhkan agar tercapainya proses operasional yang efektif dan efisien ${ }^{3}$.

Berdasarkan penjelasan diatas dapat diketahui pentingnya analisis terhadap proses manajemen obat harus dilakukan, karena ketidakefisienan dan ketidaklancaran manajemen obat akan memberikan dampak negatif, bagi kegiatan pelayanan kefarmasiaan dalam penyediaan pelayanan kesehatan secara keseluruhan, baik secara medik, sosial maupun secara ekonomi. Seorang petugas pengelola obat harus mempunyai pengetahuan mengenai pengelolaan obat agar tersedianya obat dengan mutu yang baik dan tersedia dalam jenis dan jumlah yang sesuai dengan kebutuhan pelayanan kefarmasian sehingga ketersediaan sumber daya manusia kesehatan yang berkualitas juga memegang peranan penting dalam peningkatan mutu pelayanan kesehatan, termasuk apoteker sebagai tenaga kesehatan yang berperan dalam memberikan pelayanan kefarmasian yang menyediakan pelayanan langsung dan bertanggung jawab kepada pasien yang berkaitan dengan sediaan farmasi serta berperan dalam pengendalian mutu sediaan farmasi, pengamanan, pengadaan, penyimpanan dan pendistribusian atau penyaluran obat, pengelolaan obat, pelayanan obat atas resep dokter, dan pelayanan informasi obat ${ }^{4}$.
Indikator pengelolaan obat yaitu kesesuaian item obat yang tersedia berdasarkan DOEN, kesesuaian ketersediaan obat dengan pola penyakit, tingkat ketersediaan obat, ketepatan permintaan obat, ketepatan distribusi obat, persentase dan nilai obat rusak/kadaluarsa, persentase rata-rata bobot dari variasi persediaan, persentase rata-rata waktu kekosongan obat, persentase obat yang tidak diresepkan, persentase penulisan resep obat generik $^{5,6}$. Pada penelitian ini digunakan salah satu indikator yaitu tingkat ketersediaan obat karena indikator ini cukup penting dan berkaitan dengan semua indikator lain satu sama lain dalam mempengaruhi pengelolaan obat. Dalam penelitian ini akan membahas hubungan antara tingkat pengetahuan petugas pengelola obat dengan tingkat ketersediaan obat di beberapa puskesmas Kota Malang berdasarkan metode clustered random sampling dengan pemilihan sampel ditentukan dengan metode total sampling. Berdasarkan uraian diatas, maka perlu dilakukan penelitian ini dilakukan dengan harapan mendapatkan suatu gambaran mengenai hubungan antara tingkat pengetahuan petugas pengelola obat dengan tingkat ketersediaan obat di beberapa puskesmas Kota Malang. Peneliti mengambil puskesmas pada daerah Kota Malang dengan alasan untuk mengetahui tingkat ketersediaan obat terhadap pengetahuan petugas pengelolaan obat.

\section{Metode}

Rancangan penelitian yang digunakan dalam penelitian ini, merupakan studi observasional analitik dengan pendekatan cross sectional. Rancangan dan pendekatan ini bermaksud dengan melihat gambaran yang terjadi dalam populasi tertentu. Penelitian ini menggambarkan hubungan antara tingkat pengetahuan petugas pengelola obat dengan tingkat ketersediaan obat di beberapa puskesmas.

Populasi penelitian ini adalah seluruh petugas pengelola obat yang berlatar belakang pendidikan kefarmasian maupun non kefarmasian yang bekerja di Puskesmas Kota Malang. Sampel yang digunakan dalam penelitian ini adalah seluruh petugas pengelola obat yang berlatar belakang Pendidikan kefarmasiaan maupun non kefarmasian yang bekerja di Puskesmas Kota Malang yang memenuhi kriteria inklusi. Kriteria inklusi meliputi:

1. Petugas pengelola obat di puskesmas yang bersedia menjadi responden

2. Petugas pengelola obat di puskesmas yang bersedia memberikan informasi terkait data LPLPO dan data ketersediaan obat dalam periode \pm 3 bulan terakhir

3. Petugas pengelola obat yang bersedia mengisi kuesioner penelitian

4. Petugas pengelola obat yang sudah berpengalaman di bidang pengelolaan selama $\geqslant 1$ tahun 
Jumlah sampel puskesmas dalam penelitian ini yang diambil secara acak dari masing-masing kecamatan yang terdiri dari 2 puskesmas tiap kecamatannya antara lain: Puskesmas A, Puskesmas B, Puskesmas C, Puskesmas D, Puskesmas E, Puskesmas F, Puskesmas G, Puskesmas H, Puskesmas I dan Puskesmas J.

Instrumen penelitian ini yang digunakan yaitu satu buah kuesioner tingkat pengetahuan petugas pengelola obat dan lembar pengumpul data tingkat ketersediaan obat yang dilihat dari data LPLPO.

Kemudian dilakukan uji validitas dan uji reabilitas pada instrument penelitian yaitu kuesioner tingkat pengetahuan petugas pengelola obat. Dilakukan uji validitas dan uji reabilitas pada 10 sampel responden yang telah merupakan petugas pengelola obat yang melakukan pengelolaan obat obat di Puskesmas Kota Malang yang sesuai dengan kriteria inklusi penelitian akan tetapi tidak digunakan sebagai sampel penelitian. Kuesioner yang akan diukur menggunakan pilihan jawaban yang terdiri dari jawaban benar dan jawaban salah kemudian jumlah skor setiap sampel penelitian dikategorikan kedalam tiga kategori yaitu Baik, Cukup, dan kurang .Semakin tinggi jumlah skor yang didapatkan maka tingkat pengetahuan petugas pengelola obat semakin baik. Nilai korelasi spearman, tingkat korelasi antar variabel berada diantara -1 higga 1. Nilai $r=+1$ menunjukkan hubungan positif sempurna, sedangkan $r=-1$ menunjukkan hubungan negative sempurna.

\section{Hasil dan Diskusi}

Jumlah responden pada penelitian ini adalah 25 responden petugas pengelola obat untuk 10 puskesmas Kota Malang, dengan jumlah responden pada masingmasing puskesmas adalah sebagai berikut:

Tabel 1. Jumlah Responden Dimasing-masing Puskesmas Kota

\begin{tabular}{ccc}
\multicolumn{3}{c}{ Malang } \\
\hline No. & Puskesmas & $\begin{array}{c}\text { Jumlah } \\
\text { Responden }\end{array}$ \\
\hline 1. & A & 3 orang \\
\hline 2. & B & 2 orang \\
\hline 3. & C & 3 orang \\
\hline 4. & D & 3 orang \\
\hline 5. & E & 2 orang \\
\hline 6. & F & 3 orang \\
\hline 7. & G & 2 orang \\
\hline 8. & H & 2 orang \\
\hline 9. & I & 3 orang \\
\hline 10. & J & 2 orang \\
\hline & Total & 25 orang
\end{tabular}

Pada penelitian yang dilalukan, diperoleh data demografi yaitu: jenis kelamin, usia, jabatan, tingkat pendidikan, lama bekerja, hari bekerja dan jam bekerja.

Tabel 2. Data Demografi Responden

\begin{tabular}{|c|c|c|}
\hline Demografi & Jumlah & $\%$ \\
\hline \multicolumn{3}{|l|}{$\begin{array}{c}\text { Jenis } \\
\text { Kelamin }\end{array}$} \\
\hline Pria & 4 orang & $16 \%$ \\
\hline Wanita & 21 orang & $84 \%$ \\
\hline Total & 25 orang & $100 \%$ \\
\hline \multicolumn{3}{|l|}{ Usia } \\
\hline $26-35$ & 9 orang & $36 \%$ \\
\hline $36-45$ & 11 orang & $44 \%$ \\
\hline $46-55$ & 4 orang & $16 \%$ \\
\hline $55-65$ & 1 orang & $4 \%$ \\
\hline Total & 25 orang & $100 \%$ \\
\hline \multicolumn{3}{|l|}{ Jabatan } \\
\hline $\begin{array}{c}\text { Penanggung } \\
\text { Jawab } \\
\text { Ruang } \\
\text { Farmasi } \\
\end{array}$ & 10 orang & $40 \%$ \\
\hline $\begin{array}{l}\text { Staf Ruang } \\
\text { Farmasi }\end{array}$ & 15 orang & $60 \%$ \\
\hline Total & 25 orang & $100 \%$ \\
\hline \multicolumn{3}{|l|}{ Pendidikan } \\
\hline SMF & 3 orang & $12 \%$ \\
\hline D3 Farmasi & 12 orang & $48 \%$ \\
\hline $\begin{array}{c}\text { Profesi } \\
\text { Apoteker }\end{array}$ & 9 orang & $36 \%$ \\
\hline $\begin{array}{l}\text { Magister } \\
\text { Farmasi }\end{array}$ & 1 orang & $4 \%$ \\
\hline Total & 25 orang & $100 \%$ \\
\hline \multicolumn{3}{|l|}{$\begin{array}{l}\text { Lama } \\
\text { Kerja }\end{array}$} \\
\hline $1-5$ tahun & 7 orang & $28 \%$ \\
\hline$>5-10$ tahun & 4 orang & $16 \%$ \\
\hline$>10$ tahun & 14 orang & $56 \%$ \\
\hline Total & 25 orang & $100 \%$ \\
\hline \multicolumn{3}{|l|}{ Hari Kerja } \\
\hline $\begin{array}{c}6 \\
\text { Hari/minggu }\end{array}$ & 25 orang & $100 \%$ \\
\hline Total & 25 orang & $100 \%$ \\
\hline \multicolumn{3}{|l|}{ Jam Kerja } \\
\hline \pm 7 jam/hari & 25 orang & $100 \%$ \\
\hline Total & 25 orang & $100 \%$ \\
\hline
\end{tabular}

Jenis kelamin responden yang bekerja di ruang farmasi terbanyak adalah 21 responden perempuan dengan presentase sebesar $84 \%$ dibandingkan laki - laki yang hanya berjumlah 4 responden dengan persentase $16 \%$.Pada hal ini menyatakan bahwa tidak ada perbedaan yang cukup signifikan antara jenis kelamin laki-laki dengan jenis perempuandalam memberikan jawaban terhadap tingkat ketersediaan obat dalam pengelolaan obat ${ }^{7}$. Jabatan responden dimana responden yang memiliki jabatan sebagai penanggung jawab ruang farmasi didapatkan sebanyak 10 responden dengan nilai presntasenya sebesar $40 \%$, sedangkan responden yang memiliki jabatan sebagai staff ruang farmasi sebanyak 15 responden dengan nilai presentase sebesar $60 \%$.

Usia responden yang paling banyak adalah responden dengan rentang usia $36-45$ tahun yang 
berjumlah 11 responden dengan persentase $44 \%$ dan paling sedikit adalah responden dengan rentang usia 55-65 tahun yang berjumlah 1 responden dengan persentase $4 \%$. Pada rentang usia ini akan memiliki lebih banyak pengalaman dan pemahaman sehingga bahwa usia dapat mempengaruhi kualitas daya tangkap dan pola pikir seseorang dimana semakin banyaknya bertambah usia maka semakin banyak juga pengalaman hidup maupun pengalaman kerja setiap individu, sehingga hal itu dapat mempengaruhi pengetahuan dalam pengelolaan obat terutama pada indikator untuk mempertahankan tingkat ketersediaan obat, akan tetapi tidak individu yang memiliki usia rendah tidak memiliki pengetahuan yang tinggi, karena terkadang usia yang muda juga memiliki rasa semangat dalam bekerja sehingga tingkat keinginannya tinggi hanya saja masih mempunyai pengalaman yang sedikit ${ }^{8}$.

Pendidikan pada responden memiliki peran cukup penting terkait pengelolaan obat di Puskesmas, dimana persentase pendidikan terbesar terdapat pada kategori D3 Farmasi yaitu sebanyak $48 \%(n=12)$ dan pada persentase yang terkecil didapatkan pada kategori Magister Farmasi yaitu dengan persentase sebanyak 4\% $(n=1)$. Menurut Notoatmodjo (2007) semakin tinggi pendidikan maka akan semakin banyak pengetahuan yang didapatkan. Namun tidak berarti bahwa pendidikan yang rendah akan memiliki pengetahuan yang rendah pula. Peningkatan pengetahuan tidak mutlak dipengaruhi oleh pendidikan formal, melainkan dapat dipengaruhi oleh faktor lain seperti pengalaman dan kemudahan mengakses informasi dimedia internet ${ }^{9}$.

Data mengenai lama bekerja responden pun didapatkan pada penelitian ini dimana persentase terbanyak pada rentang bekerja selama $>10$ tahun yaitu sebanyak $56 \%(\mathrm{n}=14)$, kemudian dilanjutkan pada rentang bekerja selama 1-5 Tahun yaitu sebanyak $28 \%(n=7)$ dan terakhir pada persentase yang terkecil didapatkan pada rentang bekerja selama >5-10 Tahun yaitu dengan persentase sebanyak $16 \%(n=4)$. Dari hasil penelitian didapatkan responden terbanyak pada kategori bekerja lebih 10 tahun dimana responden dengan lama bekerja lebih dari 10 Tahun memiliki tingkat pengetahuan yang baik dimana pengalaman selama bekerja lebih banyak oleh karena itu seseorang akan lebih terbiasa dalam pengelolaan obat di Puskesmas. Hal itu tersebut menunjukkan juga mayoritas responden memiliki pengalaman kerja yang cukup lama yaitu $>10$ tahun. DimanaPengalaman yang terus berkembang dalam bekerja dapat memberikan pengaruh terhadap pengetahuan dan keterampilan seseorang dalam melakukan kegiatannya Semakin lama masa kerja seseorang maka akan semakin terampil dalam melakukan suatu pekerjaan dibandingkan dengan seseorang yang memiliki masa kerja relatif singkat ${ }^{9}$, selain itu juga ditambahkan menurut (Aryani dkk, 2016) dimana Semakin banyak pengalaman petugas dalam mengelola obat maka dapat juga mempengaruhi pengetahuan petugas mengenai pengelolaan obat tersebut ${ }^{10}$.
Pendidikan memiliki pengaruh pada tingkat kemampuan berpikir, dengan kata lain seseorang dengan pendidikan lebih tinggi akan dapat mengambil keputusan yang lebih rasional. Semakin tinggi pendidikan seseorang, semakin tinggi pula ia menerima informasi dan besar pengaruhnya terhadap perubahan perilaku yang lebih baik $^{11}$

Semua responden penilitian memiliki hari kerja yang sama dalam yaitu selama 6hari dalam seminggu. Hal tersebut menandakan bahwa semua petugas pengelola obat yang menjadi responden penelitian ini mengikuti aturan dari dinas kesehatan dimana mereka semua bekerja dari hari Senin hingga Sabtu, semua responden dalam penelitian ini memiliki waktu bekerja selama 7 jam dalam sehari.

Berikut adalah Kuesioner yang digunakan sebagai alat ukur tingkat pengetahuan petugas pengelola obatKuesioner ini merupakan kuisioner yang diambil dari kuesioner penelitian oleh Nur Ishmah (2019) dalam penelitiannya tentang hubungan tingkat pengetahuanpengelola obat dengan pengelolaan obat ${ }^{12}$ dan telahdimodifikasi oleh peneliti :

Tabel 3. Kuesioner Pengetahuan

\begin{tabular}{|c|c|c|}
\hline \multicolumn{2}{|r|}{ Pernyataan } & \multirow{2}{*}{$\begin{array}{l}\text { Indikator } \\
\text { Perencanaan }\end{array}$} \\
\hline 1. & $\begin{array}{l}\text { Pada pelaksanaan proses penyediaan } \\
\text { data pemakaian Obat, Puskesmas tidak } \\
\text { diharuskan untuk membuat LPLPO }\end{array}$ & \\
\hline 2. & $\begin{array}{l}\text { Perencanaan adalah suatu proses } \\
\text { kegiatan seleksi Sediaan Farmasi dan } \\
\text { BMHP untuk menentukan jenis dan } \\
\text { jumlah Sediaan Farmasi dalam rangka } \\
\text { pemenuhan kebutuhan Puskesmas }\end{array}$ & Perencanaan \\
\hline 3. & $\begin{array}{l}\text { Perencanaan kebutuhan Sediaan Farmasi } \\
\text { dan BMHP di Puskesmas setiap periode } \\
\text { dilaksanakan oleh Kepala Puskesmas }\end{array}$ & Perencanaan \\
\hline 4. & $\begin{array}{l}\text { Analisis ABC dan VEN merupakan } \\
\text { suatu upaya pengendalian persediaan } \\
\text { untuk mempertahankan tingkat } \\
\text { persediaan dengan mengendalikan arus } \\
\text { barang yang masuk melalui pengaturan } \\
\text { perencanaan }\end{array}$ & Perencanaan \\
\hline 5. & $\begin{array}{l}\text { Kelompok Vital (V) pada analisis VEN } \\
\text { dapat membantu pengelompokan obat- } \\
\text { obatan yang bersifat life-saving atau } \\
\text { sangat penting untuk disediakan }\end{array}$ & Permintaan \\
\hline 6. & $\begin{array}{l}\text { Kelompok B dalam Analisa ABC } \\
\text { merupakan } \\
\text { penggunaan tahunan sebanyak } 10-20 \% \\
\text { item dan menggunakan } 15-20 \% \text { dana }\end{array}$ & Permintaan \\
\hline 7. & $\begin{array}{l}\text { Permintaan Sediaan Farmasi dari Pihak } \\
\text { Puskesmas diajukan kepada Pihak PBF } \\
\text { sesuai dengan ketentuan peraturan } \\
\text { perundangundangan dan kebijakan } \\
\text { pemerintah daerah setempat }\end{array}$ & Permintaan \\
\hline 8. & $\begin{array}{l}\text { Tujuan aspek penerimaan adalah agar } \\
\text { Sediaan Farmasi yang diterima sesuai } \\
\text { dengan kebutuhan berdasarkan } \\
\text { permintaan yang diajukan oleh } \\
\text { Puskesmas, dan memenuhi persyaratan } \\
\text { keamanan, khasiat, dan mutu }\end{array}$ & Penerimaan \\
\hline 9. & $\begin{array}{l}\text { Penyimpanan Sediaan Farmasi narkotika } \\
\text { dan psikotropika disimpan bersama }\end{array}$ & Penyimpanan \\
\hline
\end{tabular}


dalam satu lemari/rak dengan Sediaan Farmasi lainnya

10. Penyimpanan dilakukan dengan tujuan agar mutu Sediaan Farmasi yang tersedia di puskesmas dapat dipertahankan sesuai dengan persyaratan yang ditetapkan

11. Masa kadaluwarsa minimal dari Sediaan Farmasi yang diterima, disesuaikan dengan periode pengelolaan di Puskesmas ditambah 2 bulan

12. Pendistribusian Sediaan Farmasi dan BMHP adalah kegiatan pengeluaran dan penyerahan Sediaan Farmasi dan BMHP secara merata dan teratur untuk memenuhi kebutuhan sub unit/satelit farmasi Puskesmas dan jaringannya

13. Pendistribusian ke sub-unit di UGD Pendistribusian dilakukan dengan cara floor stock (Sistem Persediaan Lengkap di Ruangan).

14. Pendistribusian ke sub-unit di Rawat Inap dilakukan dengan cara floor stock (Sistem Persediaan Lengkap di Ruangan).

15. Pendistribusian ke sub-unit di Rawat Jalan dilakukan dengan cara individual prescribing (Resep Perorang).

16. Penarikan sediaan farmasi yang tidak memenuhi standard/ketentuan peraturan perundang-undangan dilakukan oleh pemilik izin edar atas perintah penarikan oleh BPOM (mandatory recall)

17. Pemusnahan terhadap Sediaan Farmasi dan BMHP, salah satunya dilakukan pada Sediaan Farmasi dengan $\mathrm{H}-1$ minggu masa kadatuwarsa yang dilakukan oleh Dinas Kesehatan

18. Salah satu tahapan datam proses pemusnahan Sediaan Farmasi dan BMHP adalah perlu menyiapkan Berita Acara Pemusnahan yang dilakukan oleh Dinas Kesehatan

19. Pengendalian dilakukan dengan tujuan agar tidak terjadi kelebihan dan kekosongan obat di unit pelayanan kesehatan dasar

20. Pengendalian Sediaan Farmasi terdiri dari: pengendalian persediaan, pengendalian penggunaan, dan penanganan sediaan farmasi hilang, rusak, dan kadaluwarsa

21. Administrasi pada Ruang Farmasi Puskesmas hanya berfokus pada administrasi dalam aspek pemusnahan dan penarikan Sediaan Farmasi dan BMHP

22. Administrasi dilakukan dengan tujuan sebagai bukti bahwa pengelolaan Sediaan Farmasi dan BMHP telah dilakukan; Sumber data yang ada

23. Pemantauan dan evaluasi pengelolaan Sediaan Farmasi dan BMHP dilakukan 1 kali dalam setahun

24. Salah satu tujuan aspek pemantauan dan evaluasi pengelolaan Sediaan Farmasi dan BMHP adalah memberikan penilaian terhadap capaian kinerja pengelolaan

25. Setiap kegiatan pengelolaan Sediaan Pemantauan
Farmasi dan BMHP, harus dilaksanakan sesuai SOP yang ditetapkan oleh Kepala Bidang Pengelolaan Obat di Puskesmas atau yang ditunjuk oleh Kepala Puskesmas tersebut

Kategori tingkat pengetahuan petugas apoteker terhadap pengelolaan obat di puskesmas memiliki rata-rata sebesar $100 \%$ yang termasuk kategori baik. Sedangkan tingkat pengetahuan petugas TTK (Non Apoteker) terhadap pengelolaan obat di puskesmas memiliki rata-rata sebesar $92,86 \%$ sebanyak 14 orang yang termasuk kategori baik dan sebesar $7,14 \%$ sebanyak 1 orang yang termasuk kategori cukup.

Pada penelitian yang dilalukan, diperoleh juga data persentase tingkat ketersediaan obat di Puskesmas Kota Malang yaitu:

Tabel 4. Data Tingkat Ketersediaan Obat di Puskesmas

\begin{tabular}{cccc}
\hline No. & Puskesmas & $\begin{array}{c}\text { Persentase } \\
\text { Tingkat } \\
\text { Ketersediaan } \\
\text { Obat }\end{array}$ & Kategori \\
\hline 1 & A & $60,01 \%$ & Cukup \\
\hline 2 & B & $57,17 \%$ & Cukup \\
\hline 3 & C & $37,65 \%$ & Kurang \\
\hline 4 & D & $65,94 \%$ & Cukup \\
\hline 5 & E & $62,94 \%$ & Cukup \\
\hline 6 & F & $67,25 \%$ & Cukup \\
\hline 7 & G & $56,84 \%$ & Cukup \\
\hline 8 & H & $79,73 \%$ & Baik \\
\hline 10 & I & $81,55 \%$ & Baik \\
\hline
\end{tabular}

Berdasarkan hasil tersebut, dapat dilihat bahwa manajemen penyimpanan obat, BMHP dan alat kesehatan dari 10 puskesmas Kota Malang yang ditinjau dari tingkat ketersediaan obat didapatkan hasil yang bervariasi. Hasil persentase tersebut selanjutnya dikategorikan menjadi 3 kategori yaitu baik, cukup dan kurang. Kategori tersebut didapatkan berdasarkan hasil dari nilai rata-rata dan standar deviasi, dimana nilai standar deviasi yang didapatkan yaitu 12,72. Sehingga didapatkan presentase tingkat ketersediaan obat di Puskesmas terbesar pada kategori cukup yaitu $70 \%$ $(n=7)$.

Tabel 5. Tabulasi Silang

\begin{tabular}{|c|c|c|c|c|}
\hline No & Faktor Perancu & $\begin{array}{c}\text { Kategori } \\
\text { Faktor } \\
\text { Perancu }\end{array}$ & Rata-Rata & $\begin{array}{c}\text { Katego } \\
\text { ri }\end{array}$ \\
\hline \multirow{4}{*}{1} & \multirow{4}{*}{ Usia } & 26 - 35 Tahun & 86,67 & Baik \\
\hline & & 36 - 45 Tahun & 82,18 & Baik \\
\hline & & 46 - 55 Tahun & 85 & Baik \\
\hline & & 56 - 65 Tahun & 84 & Baik \\
\hline \multirow{3}{*}{2} & \multirow{3}{*}{$\begin{array}{c}\text { Tingkat } \\
\text { Pendidikan }\end{array}$} & SMF & 84 & Baik \\
\hline & & D3 Farmasi & 83,33 & Baik \\
\hline & & $\begin{array}{l}\text { Profesi } \\
\text { Apoteker }\end{array}$ & 85,78 & Baik \\
\hline
\end{tabular}




\begin{tabular}{lllll}
\hline \multirow{2}{*}{3} & $\begin{array}{l}\text { Magister } \\
\text { Farmasi }\end{array}$ & 84 & Baik \\
\hline \multirow{3}{*}{ Lama Bekerja } & & \\
\cline { 2 - 4 } & \multicolumn{1}{c}{ - 5 Tahun } & 85,14 & Baik \\
\cline { 2 - 4 } & $>10$ Tahun & 84 & Baik \\
\cline { 2 - 4 } & $>10$ Tahun & 84 & Baik
\end{tabular}

Berdasarkan Tabel 5 menunjukkan bahwa tingkat pengetahuan responden berdasarkan faktor perancu seperti faktor usia termasuk dalam kategori baik, berdasarkan faktor tingkat pendidikan termasuk dalam kategori baik dan berdasarkan faktor pengalaman kerja termasuk kategori baik.

Tabel 6. Uji Normalitas

\begin{tabular}{cccc}
\hline Variabel & Value & Signifikasi & Keterangan \\
& & & \\
\hline $\begin{array}{c}\text { Tingkat } \\
\text { Pengetahuan } \\
\text { Petugas }\end{array}$ & 0,884 & 0,009 & $\begin{array}{c}\text { Data } \\
\text { Berdistribusi } \\
\text { Pengelola } \\
\text { Obat }\end{array}$ \\
$\begin{array}{c}\text { Tingkat } \\
\text { Ketersediaan } \\
\text { Obat }\end{array}$ & 0,929 & 0,081 & \\
\hline Uji normal \\
\hline
\end{tabular}

ujiShapiro-Wilk dikarenakan sampel penelitian ini dibawah 50 responden, hasil uji normalitas ini menunjukkan data berdistribusi tidak normalkarena signifikansi sebesar 0,009 yaitu lebih kecil dari 0,05sehingga uji yang digunakan adalah uji korelasi Rank Spearman.Uji korelasi Rank Spearman dilakukan untuk mengetahui adanyahubungan yang berikatan maupun tidak berikatan antarvariabel terikat yaitu tingkat ketersediaan obat dengan variabel bebas yaitu tingkatpengetahuan petugas pengelola obat di Puskesmas.

Tabel 7. Uji Korelasi

\begin{tabular}{|c|c|c|c|}
\hline Variabel & $\begin{array}{c}\text { Spearman } \\
\text { Correlation }\end{array}$ & Sig. & Keterangan \\
\hline $\begin{array}{c}\text { Tingkat } \\
\text { Ketersediaan } \\
\text { Obat }\end{array}$ & 0,034 & 0,870 & $\begin{array}{c}\text { Tidak } \\
\text { Terdapat } \\
\text { Korelasi } \\
\text { yang } \\
\text { Signifiakan }\end{array}$ \\
\hline
\end{tabular}

Untuk melihat hubungan tingkat pengetahuan petugas pengelola obat dan tingkat ketersediaan obat di Puskesmas Kota Malang dilakukan ujikorelasi Rank Spearman. Variabel dikatakan memiliki hubunganjika nilai p-value < koefisien alpha sebesar 0,05. Dari hasilanalisis rank spearman yang telah dilakukan diperoleh $p$ valuesebesar 0,870 dimana hasilnya lebih dari 0,05 sehinggatidak terdapat hubungan yang signifikan antara tingkatpengetahuan petugas pengelola obat dan tingkat ketersedian obat.

Semua apoteker yang ada di puskesmas kota malang tersebut memiliki tingkat pengetahuan yang baik, dimana dengan masa kerja apoteker yang bervariasi yang terdiri dari masa kerja 1-5 tahun, >5-10 tahun bahkan ada apoteker yang sudah memiliki masa kerja $>10$ tahun. Semua apoteker tersebut di setiap puskesmas didampingi oleh 1-2 orang TTK dalam melakukan pekerjaan kefarmasian. Sebanyak 5 puskesmas yang memiliki 2 orang TTK yang mayoritas petugas TTK memiliki tingkat pengetahuan yang baik, dan sebanyak 5 puskesmas tersebut hanya memiliki satu orang TTK saja, sehingga menurut petugas tersebut beban kerja yang didapatkan cukup berat. Menurut para petugas, idealnya sumber daya manusia pada ruang farmasi di puskesmas berkisar dari 3-4 orang yang salah satunya terdiri dari apoteker, sehingga diharapkan agar dapat lebih maksimal dalam pelayanan kefarmasian. Maka dari itu diharapkan adanya penambahan sumber daya manusia pada ruang farmasi.

Guna meningkatkan pengetahuan, keterampilan, serta kinerja para petugas farmasi maka dapat dilakukannya penilaian kinerja tenaga kefarmasian, dengan tujuan dapat memberikan apresiasi dan sebagai motivasi dalam menjalankan tugas. Selain itu, para petugas dapat pula mengikuti pelatihan serta pendidikan dengan upaya peningkatan pengetahuan dan keterampilan dibidang kefarmasian yang bertujuan untuk mengembangkan potensi dan produktivitas para petugas secara optimal, sehingga diharapkan seluruh pekerjaan kefarmasian di puskesmas dapat berjalan lebih baik ${ }^{8}$.

Selain itu, informasi juga dapat mempengaruhi pengetahuan seseorang, jika semakin sering petugas mencari informasi mengenai pengelolaan obat maka wawasan atau pengetahuan tentang hal tersebut juga akan semakin meningkat. Oleh karena itu setiap tahunnya Dinas Kesehatan Kota rutin mengadakan pertemuan dengan petugas puskesmas, termasuk petugas pengelola obat. Selain adanya pertemuan rutin, petugas sering mendapatkan informasi terbaru tentang pengelolaan obat melalui alat komunikasi para petugas, sekaligus dapat berdiskusi dengan petugas di puskesmas lainnya. Lingkungan yang baik juga dapat mempengaruhi petugas dalam mendapatkan informasi yang baik pula, sehingga dengan adanya informasi yang mendukung serta lingkungan yang baik dapat meningkatkan pengetahuan yang dimiliki oleh petugas ${ }^{9}$.

\section{Daftar Pustaka}

1. Bappenas. (2009). Peningkatan Akses Masyarakat Terhadap Kesehatan yang Berkualitas.

2. Djuna, S., Arifin, M.A. \& Darmawansyah, 2014.Studi Manajemen Pengelolaan Obat di Puskesmas Labakkang Kabupaten Pangkep.

3. Mangindara et al., 2012. Analisis Pengelolaan Obat Di Puskesmas Kampala Kecamatan Sinjai Timur Kabupaten Sinjai Tahun 2011. Jurnal AKK, 1(1), pp.31 40.

4. Kementerian kesehatan RI dan JICA (Japan International Cooperation Agency). 2010. Materi 
Pelatihan Manajemen Kefarmasian Di Puskesmas. Jakarta: Kementerian Kesehatan RI

5. Kementerian Kesehatan RI. 2016. Peraturan Menteri Kesehatan Republik Indonesia Nomor 74 Tahun 2016 Tentang Standar Pelayanan Kefarmasian Di Puskesmas. Jakarta: Departemen Kesehatan RI.1

6. Kementerian Kesehatan RI. 2009. Peraturan Pemerintah Republik Indonesia Nomor 51 tahun 2009 tentang Pekerjaan Kefarmasian. Jakarta: Departemen Kesehatan RI.

7. Phau, Ian. dan Baird, Michael. (2008). Complainers versus non-complainers retaliatory responses towards service dissatisfactions. Marketing Intelligence \& Planning, 26 (6), hlm. 587-604.

8. Notoatmodjo, S. 2011. Kesehatan Masyarakat Ilmu dan Seni. Jakarta: Rineka Cipta.

9. Notoatmodjo, S. 2007. Promosi Kesehatan dan Ilmu Kesehatan. Jakarta: Rineka Cipta.

10. Aryani, Alyxia Fatma., Kusuma, Anjar Mahardian., Galistiani, Githa Fungie. 2016. Hubungan Tingkat Pengetahuan Pengelola Obat terhadap Pengelolaan Obat di Puskesmas. Jurnal Manajemen dan Pelayanan Farmasi. Volume 6 Nomor 4 - Desember 2016. Purwokerto: Fakultas Farmasi Universitas Muhamadiyah Purwokerto.

11. Astutik RY. dan Ertiana D. 2018. Anemia Dalam Kehamilan. Edisi 1, Pustaka Abadi, Jember.

12. Ishmah, Nur. 2019. Hubungan Tingkat Pengetahuan Pengelola Obat denganPengelola Obat di Beberapa Puskesmas Kabupaten Malang. Skripsi.Fakultas Kedokteran. Malang: Universitas Brawijaya. 